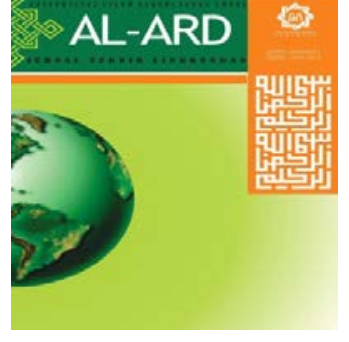

AL-ARD: JURNAL TEKNIK LINGKUNGAN

Vol.3 No.1 - September 2017(14-20)

AL-ARD

JURNAL

TEKNIK LINGKUNGAN

www.al-ard.uinsby.ac.id

\title{
STUDI PEMILIHAN TANAMAN REVEGETASI UNTUK KEBERHASILAN REKLAMASI LAHAN BEKAS TAMBANG
}

\author{
Rr Diah Nugraheni Setyowati ${ }^{1}$, Nahawanda Ahsanu Amala', Nila Nur Ursyiatur \\ Aini $^{1}$ \\ ${ }^{1}$ Fakultas Sains dan Teknologi, UIN Sunan Ampel Surabaya \\ diahnugraheni@uinsby.ac.id
}

\begin{abstract}
The contribution of the mining sector to forest destruction in Indonesia reaches $10 \%$ and now drove to 2 million ha every year. To overcome this problem, it is necessary to reclaim the former mining area. One of the determinants of the success of reclamation is plant's selection, in accordance with the condition of the land. In this case for revegetation activities need to pay attention between plant's selectionspecies and plant growth requirements with the condition of the land, so that the reclamation success criteria can be achieved. This research uses descriptive analysis method, this method is done by describing the facts which followed byanalysis and provide sufficient understanding and explanation. Techniques of data collection using comparative analysis method by comparing various journals and other literature. Criteria for selection of tree species for ex-mining land can be seen from:(1) local species of pioneer, (2) fast growing but not in high cost, (3) produces litter that easy to decompose, (4) good root system and able to do reciprocal relationship with certain microba, (5) seed carrier, (6) easy and cheap in propagation, planting and maintenance. The success of revegetation depends on several things such as: preparation of planting, crop, plant maintenance and plant monitoring.
\end{abstract}

Keywords: mining, reclamation, plant, revegetation

\begin{abstract}
Abstrak
Kontribusi sektor pertambangan terhadap kerusakan hutan di Indonesia mencapai 10\% dan kini melaju mencapai 2 juta ha tiap tahun. Untuk mengatasi hal tersebut maka perlu dilakukan reklamasi lahan bekas tambang. Salah satu penentu keberhasilan reklamasi adalah dengan pemilihan tanaman yang sesuai dengan kondisi lahan. Dalam hal ini untuk kegiatan revegetasi perlu memperhatikan antara jenis tanaman yang dipilih dan syarat tumbuh tanaman dengan kondisi lahan, agar kriteria keberhasilan reklamasi dapat tercapai. Penelitian ini menggunakan metode analisis deskriptif, metode ini dilakukan dengan cara mendeskripsikan fakta-fakta yang kemudian disusul dengan analisis dan memberikan pemahaman dan penjelasan secukupnya. Teknik pengambilan data menggunakan metode analisis komparatif dengan membandingkan berbagai jurnal maupun literature lain. Kriteria pemilihan jenis pohon untuk lahan bekas tambang dapat dilihat dari: (1) Jenis lokal pioner, (2) Cepat tumbuh tetapi tidak memerlukan biaya yang tinggi, (3) Menghasilkan serasah yang banyak dan mudah terdekomposisi, (4) Sistim perakaran yang baik dan mampu bersimbiosis atau berhubungan timbal balik dengan mikroba tertentu, (5) Merangsang datangnya vector pembawa biji, (6) Mudah dan murah dalam perbanyakan, penanaman dan pemeliharaan. Keberhasilan revegetasi bergantung pada beberapa hal seperti : persiapan penanaman, pemeliharaan tanaman serta pemantauan tanaman.
\end{abstract}

Kata kunci : pertambangan, reklamasi, tanaman, revegetasi

\section{PENDAHULUAN}

Menurut Undang-Undang Republik Indonesia Nomor 4 Tahun 2009 Tentang Pertambangan Mineral Dan Batubara, definisi pertambangan adalah sebagian atau seluruh tahapan kegiatan dalam rangka penelitian, pengelolaan dan pengusahaan mineral atau batubara yang meliputi penyelidikan umum,eksplorasi, studi kelayakan, konstruksi, penambangan, pengolahan dan pemurnian, pengangkutan dan penjualan, serta kegiatan pascatambang. Sektor pertambangan 
merupakan salah satu penggerak roda perekonomian dan pembangunan nasional yang terbesar bagi Indonesia, namun pertambangan juga dapat memberikan dampak negatif bagi kerusakan hutan. Kontribusi sektor pertambangan terhadap kerusakan hutan di Indonesia mencapai $10 \%$ dan kini melaju mencapai dua juta hektar per tahun. Di Bangka - Belitung luas lahan bekas pertambangan timah sudah mencapai 400.000 ha yang terdiri dari $65 \%$ lahan tandus dan 35\% berbentuk telagatelaga (Sitorus et al. 2008).

Pertambangan dilakukan untuk mengambil bahan tambang seperti batu bara, timah, semen, nikel, emas, dan bahan tambang lainya. Sistem pengambilan bahan tambangpun berbeda-beda, hal tersebut juga mempengaruhi keadaan muka bumi dan lingkungan. Selain merusak kondisi awal tanah, pertambangan juga dapat mempengaruhi kinerja fungsi hidrolis dalam tanah, dan dapat menurunkan tingkat produktivitas tanah (Patiung, 2011). Degradasi lahan tambang meliputi perubahan bentang alam, perubahan kondisi fisik, kimia dan biologi tanah, iklim mikro serta perubahan flora dan fauna (Siswanto dkk.,2012). Kerusakan sifat fisika dan kimia tanah diakibatkan oleh penggalian top soil untuk mencapai lapisan bahan tambang yang lebih dalam sehingga mengubah topografi dan komposisi tanah permukaan (Herjuna, 2011).

Kontribusi sektor pertambangan terhadap kerusakan hutan di Indonesia mencapai $10 \%$ dan kini melaju mencapai 2 juta ha per tahun. Untuk mengatasi hal-hal tersebut maka perlu dilakukan reklamasi lahan bekas tambang. Keberhasilan reklamasi membutuhkan pengetahuan dasar tentang lingkungan biotik dan abiotik dan juga tentang proses yang terjadi pada lingkungan pada setiap tingkatannya (Kurniawan, 2013).

Dalam melakukan reklamasi lahan bekas tambang, hal-hal yang perlu diperhatikan dan dilakukan dalam merehabilitasi/ reklamasi lahan bekas tambang yaitu dampak perubahan dari kegiatan pertambangan, rekonstruksi tanah, revegetasi, pencegahan air asam tambang, pengaturan drainase, dan tataguna lahan pasca tambang (Suprapto, 2007).

Pengembalian keadaan lahan kepada kondisi awal memerlukan waktu yang lama, karena rusak komponen-komponen tanah, kandungan bahan organik yang rendah juga menyebabkan rendahnya aktifitas dan populasi mikroba (Romero et.al., 2005). Salah satu penentu keberhasilan reklamasi salah satunya adalah dengan pemilihan tanaman yang sesuai dengan kondisi lahan. Tanaman yang sering dipilih dalam melakukan revegetasi tanah pada lahan bekas tambang biasanya dilakukan dengan menanaman tanaman akasia (A. mangium dan $A$. auriculiformis), gamal dan sengon (Setiadi, 2006). Namun pemilihan tanaman haruslah sesuai dengan kondisi lahan bekas tambang.

Reklamasi dinilai berhasil apabila telah memenuhi kriteria keberhasilan reklamasi yang ditetapkan. Dalam hal ini untuk kegiatan revegetasi perlu memperhatikan antara jenis tanaman yang dipilih dan syarat tumbuh tanaman dengan kondisi lahan, agar kriteria keberhasilan reklamasi dapat tercapai. Apabila pemilihan tanaman tepat dan sesuai terhadap kondisi lahan yang akan direklamasi, maka :

1. Tanaman dapat tumbuh dengan baik

2. Persentase tumbuh tanaman yang diinginkan tercapai

3. Jumlah tanaman tiap Hektar memenuhi target

4. Kombinasi jenis tanaman sesuai dan kesehatan tanaman baik

Jika hal tersebut terlaksana maka keberhasilan reklamasi pada aspek revegetasi dapat dikatakan berhasil karena telah sesuai dengan kriteria keberhasilan reklamasi yang ditetapkan (Parascita, 2015). Dalam hal ini menekankan bahwa untuk kegiatan revegetasi perlu memperhatikan antara jenis tanaman yang dipilih dan syarat tumbuh tanaman dengan kondisi lahan, agar kriteria keberhasilan reklamasi dapat tercapai.

\section{METODE PENELITIAN}

Jenis data yang digunakan penulis dalam penelitian ini adalah data primer dengan melakukan pengamatan dan observasi, sedangkan data sekunder yaitu data yang diperoleh dari jurnal, buku dokumentasi, dan referensi lain yang berkaitan dengan studi pemilihan tanaman revegetasi untuk keberhasilan reklamasi lahan bekas tambang. Data-data yang sudah diperoleh kemudian dianalisis dengan metode analisis deskriptif.

Metode analisis deskriptif merupakan metode penelitian yang dilakukan dengan cara mendeskripsikan fakta-fakta yang kemudian 
disusul dengan analisis dan memberikan pemahaman dan penjelasan secukupnya. Data penelitian tersebut kemudian dipaparkan secara sistematis yaitu mulai dari kriteria pemilihan jenis pohon untuk lahan bekas tambang, jenis tanaman revegetasi berdasarkan riwayat penggunaan lahan dan memaparkan contoh reklamasi lahan bekas tambang, khususnya pertambangan batu bara telah banyak dilakukan oleh perusahaanperusahaan besar yang bergerak dalam pertambangan di Indonesia.

\section{HASIL DAN PEMBAHASAN Revegetasi Lahan}

Berdasarkan

No.1211.K/008/M.PE/95
PE

reklamasi didefinisikan sebagai kegiatan yang bertujuan memperbaiki atau menata kegunaan lahan yang terganggu sebagai akibat kegiatan usaha pertambangan umum, agar dapat berfungsi dan berdaya guna sesuai dengan peruntukannya. Sesuai dengan definisinya, tujuan utama reklamasi adalah menjadikan kawasan yang rusak atau tak berguna menjadi lebih baik dan bermanfaat. Berikut adalah reklamasi lahan yang diarahkan untuk menjadi kawasan hutan melalui usaha revegetasi yang diterapkan beberapa perusahaan tambang dengan sistem terbuka.

Revegetasi menurut keputusan menteri kehutanan dan perkebunan No. 146 tahun 1999 adalah usaha atau kegiatan penanaman kembali pada lahan bekas tambang. Revegetasi dilakukan melalui tahapan kegiatan penyusunan rancangan teknis tanaman, persediaan lapangan, pengadaan bibit/ persemaian, pelaksanaan penanaman dan pemeliharaan tanaman.

\section{Kriteria Pemilihan Jenis Pohon untuk Lahan Bekas Tambang}

Menurut Maharani (2010) dalam buku reklamasi pasca tambang batubara menyatakan kriteria pemilihan jenis pohon untuk lahan bekas tambang dapat dilihat dari:

1. Jenis Lokal Pioner.

Jenis pioner memerlukan banyak cahaya dan mampu tumbuh pada lahan marginal sehingga secara teoritis cocok untuk lahan bekas tambang yang terbuka dan miskin hara. Sitorus dan Badri (2008), menyarankan untuk menggunakan jenis lokal dalam kegiatan revegetasi karena mudah beradaptasi dengan kondisi setempat yang marginal. Kemampuan adaptasi yang baik akan mengurangi resiko kegagalan dan memberikan jaminan keberhasilan pertumbuhan yang lebih baik daripada jenis yang didatangkan dari luar habitatnya.

2. Cepat tumbuh tetapi tidak memerlukan biaya yang tinggi

Jenis yang cepat tumbuh merupakan jenis yang relatif lebih efektif dalam menyerap air, unsur hara dan energi matahari serta CO2, karena percepatan pertumbuhan berkaitan erat dengan proses metabolisme fisologis terutama fotosintesa. Jenis yang cepat tumbuh biasanya relatif lebih cepat membentuk sistem percabangan untuk membentuk strata tajuk. Strata tajuk berfungsi untuk mengurangi laju angin, melindungi kerusakan fisik tanah. Tanaman yang cepat tumbuh sangat berperan dalam mempercepat proses pembentukan iklim mikro dan perbaikan kondisi tanah sehingga mempercepat proses suksesi.

3. Menghasilkan serasah yang banyak dan mudah terdekomposisi.

Sebagian besar jenis tanaman cepat tumbuh biasanya juga menghasilkan serasah yang relatif banyak dan diharapkan mudah dan cepat terdekomposisi. Serasah merupakan bahan organik penting pembentuk agregat tanah, struktur tanah dan pencegah erosi (Giddens dan Rao, 1975). Serasah berpera penting untuk meningkatkan kelembapan tanah, perbaikan sifat fisik, kimia serta biologi tanah juga dapat digunakan sebagai media tumbuh berbagai mikroorganisme sehingga tanah kaya akan bahan organik sehingga warna tanah lama-kelamaan akan menjadi coklat dan menghitam, merangsang granulasi agregat,menurunkan plastisitas, kohesi dan meningkatan kemampuan menahan air (Soepardi, 1983).

4. Sistim perakaran yang baik dan mampu bersimbiosis dan atau berhubungan timbal balik dengan mikroba tertentu.

Akar memiliki peran penting sebagai penopang tumbuhnya pohon, penyerap dan sekaligus alat transport air dan mineral bagi tanaman. Akar tanaman yang cocok untuk reklamasi lahan sebaiknya memiliki sistem perakaran yang baik dan dapat bersimbiosis dengan jamur mikoriza dan bakteri tertentu yang dapat mempercepat proses reklamasi.

5. Merangsang datangnya vector pembawa biji.

Jenis terpilih sebaiknya memiliki daya tarik bagi hadirnya satwa liar misalnya memiliki bunga, buah, biji atau daunnya disuka satwa liar. Tanaman yang biasanya disukai hewan 
karena buahnya adalah kelompoj jenis Fiscus $S p$. Satwa liar yang datang diharapkan membawa biji dalam tinja yang dibuangnya pada lahan yang direstorasi. Bila kondisi iklim mikro memungkinkan maka akantumbuh menjadi generasi baru. Dan akan lebih bagus lagi apabila biji yang dibawa dapat menggundang organisme lain yang dapat memperbaiki struktur tanah.

6. Mudah dan murah dalam perbanyakan, penanaman dan pemeliharaan.

Jenis tumbuhan terpilih seharusnya dapat memproduksi buah dalam jumlah banyak, mudah hidup serta relative murah dari segi penanaman dan pemeliharaan. Hal lain yang perlu diperhatikan untuk pemilihan tumbuhan reklamasi lahan adalah karateristik lahan yang akan ditanami, seperti informasi sifat fisik tanah, kimia tanah, curah hujan, angina, temperatur, topografi, hama, penyakit serta hewan yang ada disekitar lokasi reklamasi. Menurut Setiadi (2006) jenis tanaman yang bagus untuk reklamasi antara lain: Macaranga hypoleuca, Vitex pubescens, Trema orientalis, Endospermum diadenum, Mallotus spp., Ficus spp Hibiscus tiliaceus, Ploiarium alternifolium, Melastoma sp., Adenanthera sp, Neonauclea sp., dan Cratoxylon sp.

\section{Jenis Tanaman Revegetasi Berdasarkan Riwayat Penggunaan Lahan}

Pemilihan tanaman untuk revegetasi lahan bekas tambang harus memperhatikan riwayat penggunaan lahan. Kandungan sisa bahan tambang dapat mempengaruhi pertumbuhan tumbuhan tertantu, untuk itu perlu dilakukan identifikasi awal terkait kondisi lahan serta karateristik tanah lahan bekas tambang sebelum dilakukan reklamasi. Berikut merupakan tanaman revegetasi yang sesuai berdasarkan riwayat pemakaian lahan:

\section{Pertambangan Batu Bara}

Menurut Maharani (2010), tumbuhan revegetasi yang digunakan untuk reklamasi lahan bekas tambang batu bara meliputi: angsana (Pterocarpus indicus), johar (Cassia siamea), laban (Vitex pubescens), ketapang (Terminalia catapa), sengon (Paraserianthus falcataria), gmelina (Gmelina arborea), jabon (Anthocephalus chinensis), akasia (Acacia Mangium).

Dari hasil observasi, tumbuhan revegetasi yang paling sering digunakan adalah sengon (Paraserianthus falcataria), kelebihan dari tumbuhan ini adalah di samping mudah beradaptasi terhadap lingkungan lahan yang ditempati, sengon juga mempunyai nilai ekonomi yang tinggi, terutama dalam pengembangan bidang struktur dan infrastruktur.

2. Pertambangan Batu Apung

Menurut Dulahim (2012), tanaman revegetasi yang biasa digunakan untuk lahan bekas tambang batu apung antara lain: Mahoni (Swetenia Mahagoni), Pule (Astonia Scholaris), Trembesi (Samanea Saman), Akasia (Acacia Mangium) dan Jati (Tectano Grandis). Dari hasil observasi, semua jenis tumbuhan revegetasi yang sesuai untuk lahan bekas pertambangan batu apung mudah beradaptasi dan mempunyai keunggulan yang berbedabeda, diantaranya tumbuhan Jati (Tectano Grandis) dan Mahoni (Swetenia Mahagoni) mempunyai nilai ekonomi yang sangat tinggi, terutama dalam pengembangan bidang struktur dan infrastruktur.

Tumbuhan Trembesi (Samanea Saman) mempunyai daya serap yang cukup tinggi terhadap keberadaan $\mathrm{CO} 2$, hal ini sangat bermanfaat karena disamping untuk revegetasi lahan juga untuk membantu pemulihan udara yang tercemar.

3. Pertambangan Tanah Liat

Jenis tanaman yang digunakan untuk kegiatan revegetasi adalah tanaman kombinasi tanaman keras dan tanaman buah. Untuk tanaman keras seperti trembesi, pohon sukun, nangka dan mangga (Parascita, 2015). Jenis tumbuhan yang dapat merevegetasi lahan bekas pertambangan tanah liat disini juga mempunyai daya dukung ekonomi yang cukup tinggi, terutama pada sektor pangan.

4. Pertambangan Timah

Jenis tanaman yang sering digunakan untuk reklamasi lahan bekas pertambangan timah antara lain: Pohon Karet (Havea Brasillensis), akasia (Acacis mangium dan A. auriculiformis), gamal dan sengon (Tjahyana, 2011).

Jenis tumbuhan yang dapat merevegetasi lahan bekas pertambangan timah disini juga mempunyai daya dukung ekonomi yang cukup tinggi, terutama pada sektor pertumbuhan infrastuktur.

5. Pertambangan Tembaga

Jenis tanaman yang sesuai untuk reklamasi lahan bekas penambangan tembaga diantaranya: sengon, gamal dan akasia (Suprapto, 2007). Jenis tumbuhan yang juga dapat merevegetasi lahan bekas pertambangan tembaga disini juga 
mempunyai daya dukung ekonomi yang cukup tinggi, terutama pada sektor pertumbuhan infrastuktur wilayah sekitarnya.

\section{Reklamasi Lahan Bekas Tambang di Indonesia}

Reklamasi lahan bekas tambang, khususnya pertambangan batu bara telah banyak dilakukan oleh perusahaan-perusahaan besar yang bergerak dalam pertambangan di Indonesia, antara lain:

1. PT Berau Coal

Berdasarkan hasil dari reklamasi lahan bekas tambang yang dilakukan oleh PT. Berau Coal dengan teknik gali-isi kembali serta meminimalisasi luasan lahan terbuka didapatkan tanaman yang bagus untuk reklamasi antara lain: Kahoi (Shorea balangeran), persen hidup 69,3\%, angsana (Pterocarpus indicus) persen hidup 95,33\% dan ketapang (Terminalia cattapa) persen hidup $71,3 \%$.

2. PT. Adaro Indonesia

Revegetasi dengan jenis pionir endemik estetik yang dilakukan oleh PT. Adaro Indonesia yang bergerak dalam bidang eksplorasi dan pertambangan batu bara. Tanaman pionir endemik estetik berupa jenis cemara, eucalyptus, akasia, dan sengon menunjukan keberhasilan. Pertumbuhan tanaman terus meningkat, hal tersebut menunjukan bahwa tanaman hasil revegetasi dapat bertahan pada areal reklamasi bekas tambang.

\section{PT. Kaltim Prima Coal}

Reklamasi dan revegetasi areal bekas tambang juga dilakukan oleh PT. Kaltim Prima Coal (PT. KPC) dimulai sejak tahun 1996 sampai 2009 dengan luas lebih dari 5000 ha. Jenis yang ditanaman yang digunakan antara lain adalah johar (Cassia siamea), laban (Vitex pubescens), ketapang (Terminalia catapa), sengon (Paraserianthus falcataria),gmelina (Gmelina arborea), jabon (Anthocephalus chinensis). Tanaman hasil revegetasi pada areal bekas tambang PT. KPC kini telah membentuk ekosistem hutan dan telah mampu memberikan fungsi-fungsi hutan.

\section{PT. Jembayan Muara Bara}

Perusahaan yang bergerak dalam bidang pertambangan batu bara ini melakukan reklamasi dengan menitikberatkan multikultur revegetasi dengan penanaman berbagai jenis pionir seperti: (Macaranga gigantea, Cananga odorata, Geunsia petandra,
Gironniera nervosadan Paranephelium sp) yang dicampur dengan jenis jenis lokal (Eusideroxylon zwageri, Duriosp, Shorea spp dan beberapa jenis dari family Dipterocarpaceae). Pertumbuhan juga di dukung dengan adanya pupuk kompos dari limbah jerami masyarakat sekitar. Di beberapa lokasi telah nampak suksesi sekunder dengan mulai datangnya beberapa jenis satwa liar sebagai akibat aktifitas reklamasi yang sudah berlangsung cukup lama (Rayadin et. al. 2010).

5. PT. Multi Harapan Utama

PT. Multi Harapan Jata (PT. MHU) juga perusahaan yang bergerak dalam pertambangan batu bara. PT MHU melakukan reklamasi lahan dengan sistem revegetasi monokultur. Jenis dominan yang ditanam di PT.MHU adalah jenis jenis pionir seperti :Paraserianthes falcataria, Acacia mangium, Acacia auriculiformis, Macaranga gigantea, Vitex pinnata, Peronnema canescensdan Gliricidia moculata. Penanaman Gamal (Gliricidiasp) di lokasi reklamasi PT MHU terbukti mempunyai potensi biodiversitas flora dan fauna lebih tinggi dibandingkan jenis pionir lainnya, sehingga jenis ini dapat direkomendasian sebagai tanaman selingan di sela-sela tanaman utama (Rayadin et. al. 2011).

Keberhasilan tanaman revegetasi dapat dilihat dari struktur vegetasi dan bentuk fisik tumbuhan di hutan revegetasi pada saat pohon berumur 6 tahun, 10 tahun, dan 12 tahun. Keberhasilan revegetasi juga bergantung pada beberapa hal seperti: persiapan penanaman, pemeliharaan tanaman serta pemantauan tanaman Setiap lokasi pertambangan memiliki kondisi tertentu yang dapat mempengaruhi pelaksanaan reklamasi. Untuk itu perlu dilakukan identifikasi awal kondisi lahan untuk menentukan jenis tanaman yang akan ditanam untuk revegetasi lahan bekas tambang.

\section{KESIMPULAN}

Dari hasil penelitian pengaruh pemilihan tumbuhan revegetasi terhadap keberhasilan reklamasi lahan bekas tambang didapatkan kesimpulan sebagai berikut:

1. Pemilihan tanaman sangatlah berpengaruh terhadap keberhasilan reklamasi.

2. Kriteria pemilihan jenis tanaman untuk lahan bekas tambang meliputi: jenis lokal pioner, cepat tumbuh tetapi tidak memerlukan hara yang banyak, 
menghasilkan serasah yang banyak dan mudah terdekomposisi, sistem perakaran yang baik dan mampu bersimbiosis dengan mikroba tertentu, merangsang datangnya vector epmbawa biji, mudah dan murah dalam perbanyakan, penanaman dan pemeliharaanya.

3. Keberhasilan revegetasi bergantung pada beberapa hal seperti: persiapan penanaman, pemeliharaan tanaman serta pemantauan tanaman.

\section{DAFTAR PUSTAKA}

Abubakar, F. 2009. Evaluasi Tingkat Keberhasilan Revegetasi Lahan Bekas Tambang Nikel di PT INCO Tbk, Sorowako, Sulawesi Selatan. Institut Pertanian Bogor. Bogor.

Adi, A.N.I.Y.W., Widodo, Sri, Nurwaskito, Arif. 2017. Analisis Reklamasi Tambang Batukapur Di Kecamatan Bungoro Kabupaten Pangkep Provinsi Sulawesi Selatan. Jurnal Geomine, Vol. 5 , No. 2.

Dulahim, Hasan, M. 2012. Reklamasi Lahan Bekas Tambang Batu Gamping di Gunung Sidowayah Desa Bedoyo Kecamatan Pojong Kabupaten Gunung Kidul Provinsi Daerah Istimewa Yogyakarta. Yogyakarta: Kementrian ESDM

ESDM, 2011.Sumber Daya Batubara Indonesia Capai 105 Miliar Ton. Jakarta. http://www.esdm.go.id/berita/batubar a/44-batubara/4557-sumberdayabatubaraindonesia-capai-105-miliarton.html

Giddens, J. dan A. M. Rao. 1975. Effect of Incubation and Contact with Soil on Microbial and Nitrogen Changes in Poultry Manure. Journal Environmental Quality. Vol. 4 : 275-278.

G, Subowo. 2011. Penambangan Sistem Terbuka Ramah Lingkungan dan Upaya Reklamasi Pasca Tambang untuk Memperbaiki Kualitas Sumberdaya Lahan dan Hayati Tanah. Jurnal Sumberdaya Lahan Vol. 5 No. 2.

Hardjowigeno, S. 2003. Klasifikasi Tanah dan Pedogenesis. Akademika Pressindo, Jakarta

Herjuna, S. 2011. Pemanfaatan Bahan Humat dan Abu Terbang untuk Reklamasi Lahan Bekas Tambang. Tesis. Sekolah Pasca Sarjana. IPB. Bogor

Hermawan, B.. 2011. Peningkatan Kualitas Lahan Bekas Tambang melalui Revegetasi dan Kesesuaiannya sebagai
Lahan Pertanian Tanaman Pangan. Prosiding Seminar Nasional Budidaya Pertanian, Urgensi dan Strategi Pengendalian Alih Fungsi Lahan Pertanian. Bengkulu.

Kementerian Energi dan Sumber Daya Mineral.2008. Peraturan Menteri Energi dan Sumber Daya Mineral Nomor 18 Tahun 2008 tentang Reklamasi Dan Penutupan Tambang.

Kurniawan, Ali R, Dkk. 2013. Model Reklamasi Tambang Rakyat Berwawasan Lingkungan: Tinjauan Atas Reklamasi Lahan Bekas Tambang Batu Apung Ijobalit, Kabupaten Lombok Timur, Proponsi Nusa Tenggara Barat. Jurnal Teknologi Mineral dan Batubara Volume 9, Nomor 3, September 2013 : 165 - 174

Malau, Ruth Saurmaria., Utomo, Wani Hadi. 2017. Kajian Sifat Fisik Tanah Pada Berbagai Umur Tanaman Kayu Putih (Melaleuca Cajuputi) Di Lahan Bekas Tambang Batubara PT. Bukit Asam (Persero). Jurnal Tanah dan Sumberdaya Lahan Vol. 4, No. 2.

Maryani, I.S. 2007.Dampak Penambangan Pasir Pada Lahan Hutan Alam Terhadap Sifat Fisik,Kimia, Dan Biologi Tanah (Studi Kasus Di Pulau Sebaik Kabupaten Karimun Kepulauan Riau). Institut Pertanian Bogor. Bogor

Maharani, Rizki,Dkk. 2010. Status Riset Reklamasi Bekas Tambang Batubara: Revegetasi Lahan Bekas Tambang Batubara. Samarinda: Balai Penelitian dan Pengembangan Kehutanan

Munir. 1996. Geologi dan Mineralogi Tanah. Pustaka Jaya, Jakarta. Hlm 290.

Nurlaela, Abrar S., dan Farida P., 2014. Tanggung Jawab Hukum Reklamasi Lahan Bekas Pertambangan PT. Kaltim Prima Coal. Kabupaten Kutai Timur. Kalimantan Timur

Parascita, L., Dkk. 2015.Rencana Reklamasi Pada Lahan Bekas Penambangan Tanah Liat di Kuari Tlogowaru PT. SEMEN Indonesia (Persero) Tbk, Pabrik Tuban, Jawa Timur. Jurnal Teknologi Pertambangan Volume 1 Periode Maret Agustus. Yogyakarta: UPN Veteran.

Patiung, O.,Dkk. 2011.Pengaruh Umur Reklamasi Lahan Bekas Tambang Batubara Terhadap Fungsi Hidrolis. Jurnal Hidrolitan, Vol $2: 2: 60-73$, ISSN 2086-4825 
Prayogo, Dody. 2008. Social Justice dan Distributive Welfare Dalam Industri Tambang dan Migas di Indonesia, Jurnal Galang Volume 3 No. 3.

Purnomo, D.W., Magandhi, Mahat., Helmanto, Hendra., Witono, Joko Ridho. 2015. Jenis-Jenis Tumbuhan Reklamasi Potensial Untuk Fitoremediasi di Kawasan Bekas Tambang Emas. Pros Sem Nas Masy Biodiv Indon Volume 1, Nomor 3.

Pujawati, E. D., 2009. Jenis-jenis Fungi Tanah pada Areal Revegetasi Acacia Mangium Willd di Kecamatan Cempaka Banjarbaru..Jurnal Hutan Tropis Borneo Volume 10 (28), Edisi Desember 2009.

Purnamayani, R., J. Hendri, dan H. Purnama.2016. Karakteristik Kimia Tanah Lahan Reklamasi Tambang Batubara di Provinsi Jambi.Prosiding Seminar Nasional Lahan Suboptimal 2016, Palembang.

Rayadin, Y., Boer, C., Soetedjo, Suba, R.B., Syoim, M., Rochmadi, S., Abadi, F. 2010.Identifikasi dan Inventarisasi Potensi Keanekaragaman Hayati (KEHATI) di Kawasan Pertambangan PT Jembayan Muara Bara. Kerjasama Pusat Penelitian Hutan Tropis (PPHT) Universitas Mulawarman dengan PT Jembayan Muara Bara, Kalimantan Timur.

Romero, E., E. Benitez and R. Nogales 2005.Suitability Of wastes From OliveOil Industry For Initial Reclamation of a pb/zn Mine Tailing. Water, Air, and Soil Pollution 165: 153-165

Setiadi, Y. 2006. Bahan Kuliah Ekologi Restorasi. Program Studi Ilmu Pengetahuan Kehutanan. Sekolah Pasca Sarjana. IPB.

Siswanto B., Krisnayani B. D., Utomo W. H., and Anderson C. W. N. 2012.Rehabilitation of Artisanal Gold Mining Land in West Lombok, Indonesia: Characterization of Overburden and The Surrounding Soils. Journal of Geology and Mining Research Vol. 4(1), Hal. 1-7, January 2012. ISSN 2006-9766.

Sitorus, S. R. P dan L. N. Badri. 2008. Karakteristik Tanah dan Vegetasi Lahan Terdegradasi Pasca Penambangan Timah serta Teknik Rehabilitasi untuk Keperluan Revegetasi.Prosiding Semiloka Nasional 22-23 Desember 2008.
Soepardi, G. 1983. Sifat dan Ciri Tanah. Jurusan Tanah. Fakultas Pertanian. IPB. Bogor

Stone. 1974. Infrastruktur. American Public Works Association. USA

Suprapto, S.J. 2007. Tinjauan Reklamasi Lahan Bekas Tambang dan Aspek Konservasi Bahan Galian. Pusat Sumber Daya Geologi.

Tjahyana, B.E. dan Yulius, F. 2011. Revegetasi Lahan Bekas Tambang Timah dengan Tanaman Karet (Hevea Brasilliensis). Balai Penelitian Tanaman Rempah dan Aneka Tanaman Industri 